\title{
Chemical composition and antioxidant activity of lichen Toninia candida
}

\author{
Nedeljko T. Manojlovic, ${ }^{*}$ I Perica J. Vasiljevic, ${ }^{2}$ Pavle Z. \\ Maskovic $^{3}$
}

${ }^{1}$ Department of Pharmacy, Medical Faculty, University of Kragujevac, Serbia, ${ }^{2}$ Department of Biology, Faculty of Science, University of Nis, Serbia,

${ }^{3}$ Faculty of Agronomy, University of Kragujevac, Serbia.

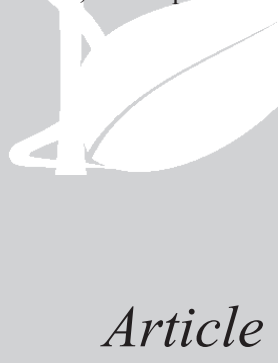

\begin{abstract}
In the present investigation, methanol, chloroform and petrol ether extracts from the lichen Toninia candida (Weber) Th. Fr, Catillariaceae, were assayed for their antioxidant activity. The phenolic composition of the extracts was determined by HPLC-UV analysis. The predominant phenolic compound in all the extracts was depsidone, norstictic acid. All the tested extracts of $T$. candida contain, besides norstictic acid, atranorin, stictic, protocetraric and usnic acid, but in different amounts and relations. The lichen extracts showed comparable and strong antioxidant activity, exhibited higher DPPH and hydroxyl radical scavengings, chelating activity and inhibitory activity towards lipid peroxidation. This is the first report of chemical composition and antioxidant antimicrobial activity of the lichen Toninia candida.
\end{abstract}

Received 20 Jan 2011

Accepted 12 Jul 2011

Available online 7 Oct 2011

Keywords: antioxidant activity chemical composition HPLC

Toninia candida

ISSN 0102-695X http://dx.doi.org/10.1590/S0102$695 \times 2011005000184$

\section{Introduction}

Lichens are valuable plant resources and are used as food, fodder, medicine, dyes perfume, spice, and for miscellaneous purposes throughout the world. More than one thousand primary and secondary metabolites with identified structures are currently known in lichens (Shukla et al., 2010). The use of lichens in medicine is based on the fact that they contain unique and varied biologically active substances. Lichen metabolites exert a wide variety of biological actions including antibiotic, antimycobacterial, antiviral, anti-inflammatory, analgesic, antipyretic, antiproliferative and cytotoxic effects (Huneck, 1999; Shukla et al., 2010; Manojlovic et al., 2002; Manojlovic et al., 2010a; Manojlovic et al., 2010b; Manojlovic et al., 2010c). Even though these manifold activities of lichen metabolites have now been recognized, their therapeutic potential has not yet been fully explored and thus remains pharmaceutically unexploited.

The most numerous classes of secondary metabolites are depsides and depsidones. Depside molecules consist of 2-4 hydroxybenzoic acid residues linked by ester groups. Many depsides reported in literature have been found to possess important physiological properties. The antioxidant property has been reported in depsides isolated from various lichen species (Hidalgo et al., 1994). More than one hundred compounds are depsidones, which have an additional ether bond between aromatic rings. Depsidones in lichen are believed to arise by oxidative cyclisation of depsides. It has been found that depsidones are more efficient antioxidants than depsides. The higher efficiency of the depsidones could be related to a larger incorporation into lipidic microdomains (Hidalgo et al., 1994). Depsidone and depside compounds such as pannarin, 10chloropannarin and sphaerophorin, tested in cell cultures of lymphocytes, were shown to have a higher cytotoxic effect than colchicine (Correche' et al., 2002). The depsidones salazinic acid, stictic acid and psoromic acid were the most apoptotic active derivatives among fifteen lichen compounds evaluated on primary cultures of rat hepatocytes (Correche' et al., 2002). Toninia candida (Weber) Th. Fr, Catillariaceae, is widely distributed in continental areas in the Northern Hemisphere (Timdal, 1991). In Serbia, T. candida could be found in Jelasnica gorge (Mt. Suva Planina) on a vertical limestone rocks.

Thus, the aim of the present work was to identify and quantify phenolic acids composition of Toninia candida lichen by HPLC-UV and to evaluate the antioxidant capacity of methanol, chloroform and petrol ether extracts from this lichen using different systems, including DPPH and hydroxyl radical scavenging, metal chelating activity, as well as to screen their antimicrobial activity.

\section{Material and Methods}

\section{Lichen material}


The lichen material of Toninia candida (Weber) Th. Fr, Catillariaceae, was collected from Mt. Suva (Jelasnica gorge) in Serbia during October 2010. A voucher specimen (HMN 5459) has been deposited at the Herbarium Moesiacum Nis in the Department of Biology and Ecology, Faculty of Sciences and Mathematics, University of Nis, Serbia.

\section{Preparation of the lichen extracts}

The lichen material was air-dried at room temperature $\left(26^{\circ} \mathrm{C}\right)$ for one week, after which it was ground to a uniform powder. Each extract (methanol, chloroform and petrol ether) extract was prepared by soaking $500 \mathrm{~g}$ dry powdered lichen material in $2000 \mathrm{~mL}$ of solvent at room temperature for three days. The extracts were filtered through a Whatman no. $42(125 \mathrm{~mm})$ filter paper and concentrated using a rotary evaporator.

\section{Instrumentation and conditions}

HPLC analysis was carried out on an Agilent 1200 Series HPLC instrument with C18 column (C18; 25 $\mathrm{cm} \times 4.6 \mathrm{~mm}, 10 \mathrm{~m}$ ) and a UV spectrophotometric detector with methanol-water-phosphoric acid (80:20:0.9, v/v/v) solvent. Methanol was of HPLC grade and was purchased from Merck (Darmstadt, Germany). Phosphoric acid was analytical-grade reagent. Deionized water used throughout the experiments was generated by a Milli-Q academic water purification system (Milford, MA, USA). The sample injection volume was $10 \mathrm{~mm}^{3}$. The flow rate was $1.0 \mathrm{~mL} / \mathrm{min}$. The standards used were obtained from the following sources: norstictic acid $\left(2, \mathrm{t}_{\mathrm{R}}=4.01 \pm 0.20\right.$ min) was isolated from lichen Ramalina furinacea, stictic acid $\left(1, \mathrm{t}_{\mathrm{R}}=3.31 \pm 0.01 \mathrm{~min}\right)$ from lichen Xanthoparmelia conspersa, protocetraric acid $\left(3, \mathrm{t}_{\mathrm{R}}=4.28 \pm 0.05 \mathrm{~min}\right)$ from lichen Cetraria islandica, usnic acid $\left(5, \mathrm{t}_{\mathrm{R}}=14.54 \pm 0.30\right.$ $\min )$ and atranorin $\left(6, \mathrm{t}_{\mathrm{R}}=16.47 \pm 0.30 \mathrm{~min}\right)$ from lichen Evernia prunastri. The standard samples were isolated in our laboratory and their structures were confirmed by spectral data. The retention times and UV spectra of these standards are shown in Table 2 and Figure 1.

Reference solutions of decreasing concentrations were obtained by dilution with eluent of the requisite standard solution. These solutions were analyzed and the corresponding peak areas plotted against the concentration of acid injected. The concentrations of the components in the analyzed samples (were calculated from the chromatogram peak areas using the normalization method. The identification of the different compounds was achieved by comparison of both $\mathrm{tR}$ and the absorption spectra obtained for each diluted peak with those obtained for the standards. The data obtained were statistically processed by using a standard non-parametric variance analysis method (ANOVA) for determining significant intergroup differences. Data are presented as the mean \pm standard deviation (SD) of three separate experiments performed on different samples.

LC-MS/MS analysis was carried out using an Agilent 1100 LC system consisting of degasser, binary pump, auto sampler, and column heater. The column outlet was coupled to an Agilent MSD Ion Trap XCT mass spectrometer equipped with an ESI ion source. For the chromatographic separation, a Zorbax 300Ĺ Extend-C18 Column $(2.1 \times 150 \mathrm{~mm}, 1.8 \mu \mathrm{m})$ was used. The mobile phase was pumped at $1 \mathrm{mLmin}^{-1}$ flow rate and consisted of methanol-water-formic acid (80:20:0.9, v/v/v).

\section{Determination of the total phenolics}

The total phenolics content was determined using the Folin-Ciocalteau method (Singleton et al.,1999). Extract was diluted to the concentration of 1 $\mathrm{mg} / \mathrm{mL}$, and aliquots of $0.5 \mathrm{~mL}$ were mixed with $2.5 \mathrm{~mL}$ of FC reagent (previously diluted 10-fold with distilled water) and $2 \mathrm{~mL}$ of $\mathrm{NaHCO}_{3}(7.5 \%)$. After $15 \mathrm{~min}$ of staying at the $45^{\circ} \mathrm{C}$ the absorbance was measured at 765 $\mathrm{nm}$ on spectrophotometer versus blank sample. Total phenols were determined as gallic acid equivalents (mg $\mathrm{GA} / \mathrm{g}$ extract), and the values are presented as means of triplicate analyses.

\section{Determination of total antioxidant capacity}

The total antioxidant activity of the Toninia candida extract was evaluated by the phosphomolybdenum method (Prieto et al., 1999). The assay is based on the reduction of Mo (VI)-Mo (V) by the antioxidant compounds and subsequent formation of a green phosphate/Mo (V) complex at acid pH. $0.3 \mathrm{~mL}$ of sample extract was combined with $3 \mathrm{~mL}$ of reagent solution (0.6 M sulfuric acid, $28 \mathrm{mM}$ sodium phosphate and $4 \mathrm{mM}$ ammonium molybdate). The tubes containing the reaction solution were incubated at $95{ }^{\circ} \mathrm{C}$ for $90 \mathrm{~min}$. Then the absorbance of the solution was measured at 695 $\mathrm{nm}$ using spectrophotometer against blank after cooling to room temperature. Methanol $(0.3 \mathrm{~mL})$ in the place of extract was used as the blank. Ascorbic acid (AA) was used as standard and the total antioxidant capacity is expressed as milligrams of ascorbic acid per gram of the dry extract.

\section{Determination of DPPH free radical scavenging activity}

The method used by (Takao et al., 1994) was adopted with suitable modifications from (Kumarasamy et al., 2007). DPPH (8 mg) was dissolved in $\mathrm{MeOH}$ (100 $\mathrm{mL}$ ) to obtain a concentration of $80 \mu \mathrm{g} / \mathrm{mL}$. Serial dilutions were carried out with the stock solution $(1 \mathrm{mg} / \mathrm{mL})$ of the extract. Solutions ( $2 \mathrm{~mL}$ each) were then mixed with DPPH 
$(2 \mathrm{~mL})$ and allowed to stand for 30 min for any reaction to occur, and the absorbance was measured at $517 \mathrm{~nm}$. Ascorbic acid (AA), gallic acid (GA) and butylated hydroxytoluene (BHT) were used as reference standards and dissolved in methanol to make the stock solution with the same concentration $(1 \mathrm{mg} / \mathrm{mL})$. Control sample was prepared containing the same volume without test compounds or reference antioxidants. Methanol 95\% was used as blank. The DPPH free radical scavenging activity (\%) was calculated using the following equation:

$$
\% \text { inhibition }=\frac{A c-A s}{A c} \times 100
$$

The IC50 value, which is the concentration of the test material that reduces $50 \%$ of the free radical concentration, was calculated as $\mu \mathrm{g} / \mathrm{mL}$ through sigmoidal dose-response curve.

Determination of the inhibitory activity toward lipid peroxidation

The antioxidant activity was determined by the thiocyanate method (Hsu et al., 2008). Serial dilutions were carried out with the stock solution $(1 \mathrm{mg} / \mathrm{mL})$ of the extracts, and $0.5 \mathrm{~mL}$ of each solution was added to linoleic acid emulsion (2.5 mL, $40 \mathrm{mM}, \mathrm{pH}$ 7.0). The linoleic acid emulsion was prepared by mixing 0,2804 $\mathrm{g}$ linoleic acid, $0.2804 \mathrm{~g}$ Tween-20 as emulsifier in 50 $\mathrm{mL} 40 \mathrm{mM}$ phosphate buffer and the mixture was then homogenized. The final volume was adjusted to $5 \mathrm{~mL}$ with $40 \mathrm{mM}$ phosphate buffer, $\mathrm{pH}$ 7.0. After incubation at $37^{\circ} \mathrm{C}$ in the dark for $72 \mathrm{~h}$, a $0.1 \mathrm{~mL}$ aliquot of the reaction solution was mixed with $4.7 \mathrm{~mL}$ of ethanol $(75 \%), 0.1$ $\mathrm{mL} \mathrm{FeCl}(20 \mathrm{mM})$ and $0.1 \mathrm{~mL}$ ammonium thiocyanate (30\%). The absorbance of this mixture was measured at $500 \mathrm{~nm}$, after it was stirred for $3 \mathrm{~min}$. Ascorbic acid, gallic acid, $\alpha$-tocopherol and BHT were used as a reference compounds. To eliminate the solvent effect, the control sample, which contained the same amount of solvent added to the linoleic acid emulsion in the test sample and reference compound, was used. Inhibition percent of linoleic acid peroxidation was calculated using following formula:

$$
\% \text { inhibition }=\frac{A c-A s}{A c} \times 100
$$

\section{Measurement of ferrous ion chelating ability}

The ferrous ion chelating ability was measured by the decrease in absorbance at $562 \mathrm{~nm}$ of the iron (II)ferrozine complex (Carter, 1971; Yan et al., 2006). One milliliter of $0.125 \mathrm{mM} \mathrm{FeSO}_{4}$ was added to $1.0 \mathrm{~mL}$ sample (with different dilutions), followed by $1.0 \mathrm{~mL}$ of 0.3125 $\mathrm{mM}$ ferrozine. The mixture was allowed to equilibrate for
10 min before measuring the absorbance. The ability of the sample to chelate ferrous ion was calculated relative to the control (consisting of iron and ferrozine only) using the formula:

$$
\text { Chelating effect }(\%)=\frac{A c-A s}{A c} \times 100
$$

\section{Determination of hydroxyl radical scavenging activity}

The ability of Toninia candida to inhibit non site-specific hydroxyl radical-mediated peroxidation was carried out according method described by Hinneburg et al. (2006). The reaction mixture contained $100 \mu \mathrm{L}$ of extract dissolved in water, $500 \mu \mathrm{L}$ of $5.6 \mathrm{mM}$ 2-deoxyD-ribose in $\mathrm{KH}_{2} \mathrm{PO}_{4}-\mathrm{NaOH}$ buffer (50 mM, pH 7.4), 200 $\mu \mathrm{L}$ of premixed $100 \mu \mathrm{M} \mathrm{FeCl}_{3}$ and $104 \mathrm{mM}$ EDTA (1:1 $\mathrm{v} / \mathrm{v})$ solution, $100 \mu \mathrm{L}$ of $1.0 \mathrm{mM} \mathrm{H} 2 \mathrm{O} 2$ and $100 \mu \mathrm{L}$ of $1.0 \mathrm{mM}$ aqueous ascorbic acid. Tubes were vortexed and incubated at $50{ }^{\circ} \mathrm{C}$ for $30 \mathrm{~min}$. Thereafter, $1 \mathrm{~mL}$ of $2.8 \%$ TCA and $1 \mathrm{~mL}$ of $1.0 \%$ TBA were added to each tube. The samples were vortexed and heated in a water bath at $50{ }^{\circ} \mathrm{C}$ for $30 \mathrm{~min}$. The extent of oxidation of 2-deoxyribose was estimated from the absorbance of the solution at $532 \mathrm{~nm}$. The percentage inhibition values were calculated from the absorbance of the control (Ac) and of the sample (As), where the controls contained all the reaction reagents except the extract or positive control substance. The values are presented as the means of triplicate analyses.

\section{Statistical analysis}

All the results are presented as mean \pm standard deviations of three determinations. Statistical analyses were performed using Student's t-test and one way analysis of variance. Multiple comparisons of means were done by LSD (least significant difference) test. A probability value of 0.05 was considered significant. All computations were made by employing the statistical software (SPSS, version 11.0). IC50 values were calculated determined by nonlinear regression analysis from the sigmoidal dose-response inhibition curve.

\section{Results and Discussion}

A representative chromatograms for standards and Toninia candida methanol, chloroform and petrol ether extracts eluted by HPLC are represented in Figure 1 and Figure 2. As it is evidenced in the chromatograms, there were the presence of depsidones as the most abundant substance class in the extracts examined. As the most abundant depsidone, norstictic acid (NOR) $\left(t_{R}=4.01 \pm 0.2\right.$ min, 2) was identified. This compound was previously reported from the family Umbilicariaceae (Narui et al., 
1996) and had been reported to demonstrate antimicrobial effect on Bacillus subtilis, Listeria monocytogenes, Proteus vulgaris, Staphylococcus aureus, Streptococcus faecalis, Aeromonas hydrophila, Candida albicans and Candida glabrat (Tay et al., 2004).

As can be seen in chromatograms, beside norstictic acid (2), stictic acid $\left(\mathrm{t}_{\mathrm{R}}=3.31 \pm 0.01 \mathrm{~min}, \mathbf{1}\right)$, protocetraric acid $\left(\mathrm{t}_{\mathrm{R}}=4.28 \pm 0.05 \mathrm{~min}, 3\right)$, usnic acid $\left(t_{R}=14.54 \pm 0.30 \mathrm{~min}, 5\right)$ and atranorin $\left(t_{R}=16.47 \pm 0.30\right.$ min, 4) were also identified. Four detected compounds belonging to the depsidones. Atranorin is depside and usnic acid is antibiotic with dibenzofurane structure. The UV spectra of depsidones have three absorption maxima and are dissimilar from those of depsides and monocyclic compounds. The UV spectra of protocetraric acid are very similar to those of norstictic acid. Absorbance maxima at 234 and $282 \mathrm{~nm}$ are characteristic for usnic acid. Except norstictic acid, other compounds were found in the extracts in small amounts. Identification of these compounds was achieved by comparison of their $\mathrm{tR}$ values with the standard substances previously isolated from lichens. The UV absorbance spectral data (200-400 $\mathrm{nm}$ ) also corresponded with those of standards and found in Refs. (Yoshimura at al., 1994; Huneck \& Yoshimura, 1996). LC-MS analysis was also used to confirm the structures of detected molecules. Values of molecular and fragmentation ions were consistent with those published in literature (Huneck \& Yoshimura, 1996). Table 2. shows the retention time of the detected lichen substances, their absorbance maxima $(\mathrm{nm})$ and fragmentation ions. All compounds are identified for the first time in this lichen.

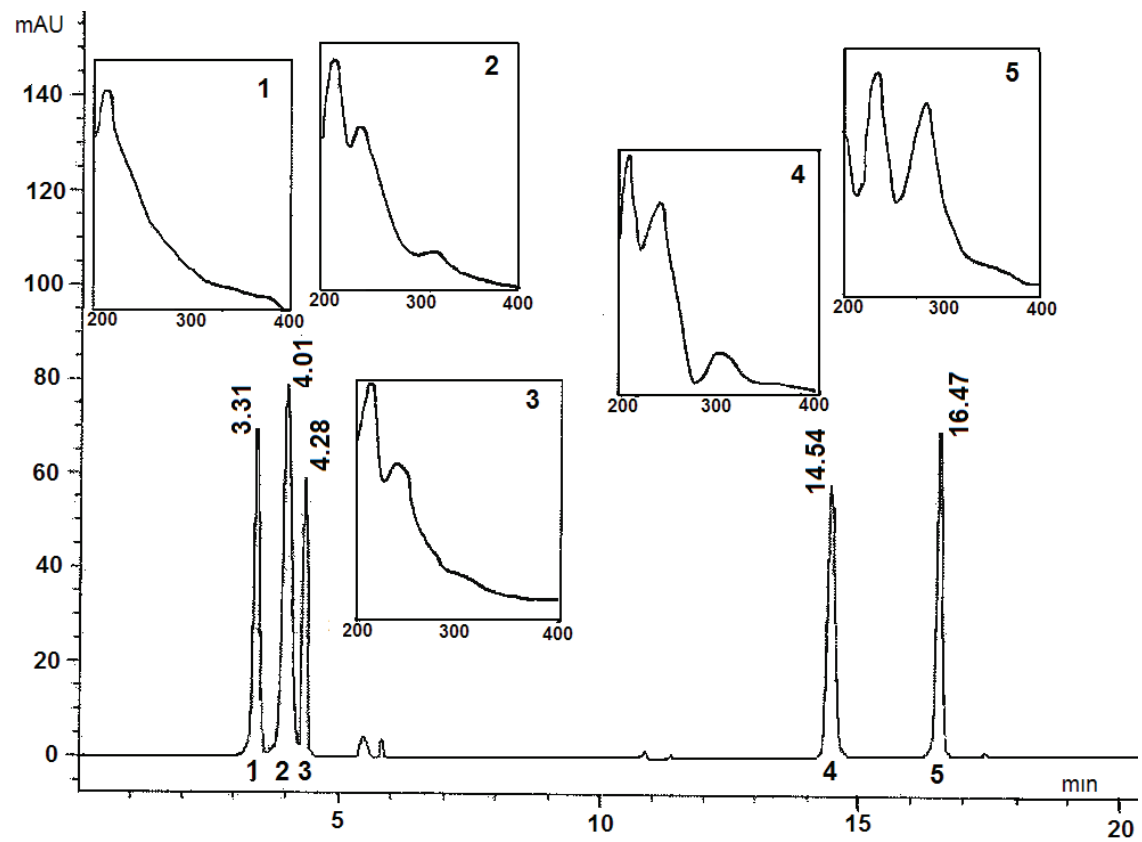

Figure 1. Chromatogram of the standards used for identification of the compounds present in the Toninia candida. In detel can be observed the UV spectra of these compounds (200-400 nm).

Table 1. The amounts of presented compounds in the lichen Toninia candida.

\begin{tabular}{lcccc}
\hline \multirow{2}{*}{ Compound } & \multirow{2}{*}{$\begin{array}{c}\text { Substance } \\
\text { class }\end{array}$} & \multicolumn{3}{c}{$\mu \mathrm{g} / \mathrm{g} \mathrm{DW}$} \\
\cline { 3 - 5 } & & MET & CHL & PET \\
\hline Stictic acid (1) & Depsidone & $2.0 \pm 0.2$ & $5.2 \pm 0.5$ & $4.7 \pm 0.2$ \\
Norstictic acid (2) & Depsidone & $51.5 \pm 1.0$ & $53.6 \pm 0.5$ & $64.3 \pm 1.0$ \\
Protocetraric & Depsidone & $0.6 \pm 0.4$ & $2.5 \pm 0.2$ & $2.1 \pm 0.4$ \\
acid (3) & Dibenzofurane & - & $0.6 \pm 0.1$ & - \\
Usnic acid (5) & Depside & - & $0.8 \pm 0.1$ & - \\
Atranorin (4) & & & & \\
\hline
\end{tabular}

Table 2. Retention time of the examined lichen substances and their absorbance maxima (nm) and fragmentation ions.

\begin{tabular}{ccccc}
\hline $\begin{array}{c}\text { Peaks } \\
\mathrm{N}^{\mathrm{o}}\end{array}$ & Compound & $\begin{array}{c}\text { Retention time } \\
\left(t_{\mathrm{R}} \pm \mathrm{SD}\right)^{*}(\mathrm{~min})\end{array}$ & $\begin{array}{c}\text { Absorbance } \\
\text { maxima }(\mathrm{nm}) \\
\mathrm{UV} \text { spectrum }\end{array}$ & $\begin{array}{c}\text { MS ions } \\
(\mathrm{m} / \mathrm{z})\end{array}$ \\
\hline 1 & Stictic acid (1) & $3.31 \pm 0.01$ & $212,236,310^{\mathrm{m}}$ & $\begin{array}{c}386,368,341, \\
314,193,191\end{array}$ \\
2 & Norstictic acid & $4.01 \pm 0.20$ & $212,239,310^{\mathrm{m}}$ & $372,354,327$, \\
& $(\mathbf{2})$ & & & $298,179,177$ \\
3 & Protocetraric & $4.28 \pm 0.05$ & $212,240,320^{\mathrm{m}}$ & $374,356,312$, \\
& acid (3) & & & $258,230,179$, \\
& & & & 151 \\
4 & Usnic acid (5) & $14.54 \pm 0.30$ & 234,282 & $344,328,260$, \\
& & & & 233,217 \\
5 & Atranorin (4) & $16.47 \pm 0.30$ & $210,252,321^{\mathrm{m}}$ & 374,196, \\
& & & & 179,164, \\
& & & & 136 \\
\hline
\end{tabular}



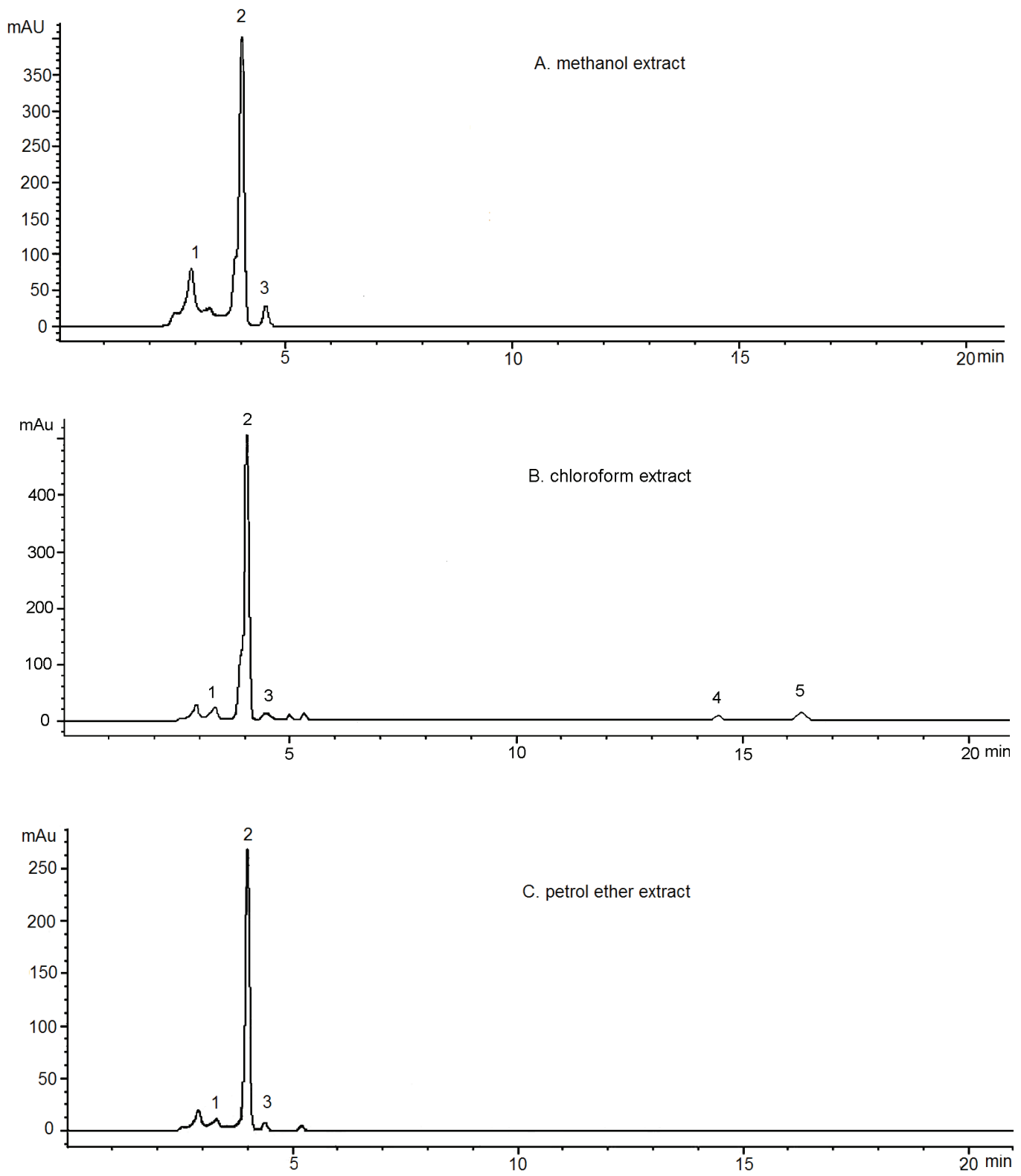

Figure 2. HPLC hromatograms acquired at $256 \mathrm{~nm}$ of the methanol (A), chloroform (B) and petrol etar (C) extracts of Toninia candida. Chromatographic peaks identities are reported in Table 2.

Phenolic compounds have been reported to be associated with antioxidative action in biological systems, mainly due to their red-ox properties, which can play an important role in absorbing and neutralizing free radicals, quenching singlet and triplet oxygen, or decomposing peroxides (Saha et al., 2008). The results of determination of total phenolic and antioxidant capacity are given in Table 3. Total phenolic contents were determined and amounted to $76.26 \pm 0.32 \mathrm{mg} \mathrm{GA} / \mathrm{g}, 45.25 \pm 0.72 \mathrm{mg} \mathrm{GA} / \mathrm{g}$ and $42.98 \pm 0.15 \mathrm{mg} \mathrm{GA} / \mathrm{g}$, for methanol, chloroform and petrol ether extracts, respectively. The results showed that the methanolic, chloroform and petroleum ether extracts possess antioxidant activity, with total antioxidant capacity of $78.45 \pm 0.58 \mu \mathrm{g} \mathrm{AA} / \mathrm{g}, 56.67 \pm 0.30 \mu \mathrm{g} \mathrm{AA} / \mathrm{g}$ and $51.45 \pm 0.31 \mu \mathrm{g} \mathrm{AA} / \mathrm{g}$, respectively.

The assessment of antioxidant activity showed that all tested extracts were able to scavenge this radical (Table 4). The chloroform extract displayed a higher activity than petrol ether and methanol extracts $(48.98 \pm 1.45, \quad 50.10 \pm 0.95$ and $51.45 \pm 1.78 \mu \mathrm{g} / \mathrm{mL}$, respectively). Although this scavenging effect was lower than that of BHT (Table 4), it was stronger than the antioxidant activity reported in many other lichen species (Gulluce et al., 2006). Results demonstrated also 
that all tested extracts exhibited significant inhibitory activity towards lipid peroxidation (from $21.45 \pm 1.55 \mu \mathrm{g}$ / $\mathrm{mL}$ to $46.46 \pm 1.68 \mu \mathrm{g} / \mathrm{mL})$. The results of metal chelating activity are also shown in the Table 4 and these values were very similar for all tested extracts.

The results of determination of hydroxyl radical scavenging activity (Table 4) showed that IC50 values were $67,11 \pm 0.23,53.23 \pm 0.51$ and $50.57 \pm 0.75 \mu \mathrm{g} / \mathrm{mL}$ for metanolic, chloroform and petrol ether extracts, respectively. These results revealed that the methanol, chloroform and petrol ethar extracts of T. candida organs were free radical scavengers, acting possibly as primary antioxidants. The strong antioxidant activity of $T$. candida assessed by the different systems could be attributed to their high total polyphenolic contents. Moreover, the high yield of the different phenolic compounds (depsidones) found in $T$. candida thallus (Table 1) might contribute to the potent antioxidant activity of the tested extracts, since a positive correlation between phenolic composition and antioxidant activity was proved (Katalinic et al., 2006). Thus, antioxidant property of the lichen could be attributed to the significant amount of depsidones, especially norstictic acid, present in our study with the high amounts of $51.5 \pm 2.0,53.6 \pm 1.0$ and $64.3 \pm 1.5 \mu \mathrm{g} / \mathrm{g}$
DW, respectively in the methanol, chloroform and petrol ether extracts. Other minor phenolic compounds should not be neglected, since synergy of the different chemicals with each other should be taken into consideration for the biological activity. The presence of the phenolic groups in the lichen metabolites is considered to be key element for the antioxidative efficiency (Markovic \& Manojlovic, 2010). Norstictic acid posesses two phenolic groups in the molecule which probably play an important role in expression of their antioxidant activity.

In conclusion, this is the first study focused on the chemical composition and biological activities of T. candida. The methanol, chloroform and petrol ether extracts of the lichen showed significant antioxidant activity. Four depsidones, one depside and usnic acid were identified, and norstictic acid was the dominant phenolic compound in the lichen. The present study provides data for supporting the use of $T$. candida extracts as natural antioxidant agents, and confirms that these extracts represent a significant source of phenolic compounds. Future investigation will be focused on isolation of phenolic compounds and determination of their biological activities in vitro and in vivo.

Table 3. Total phenolic and total antioxidant capacity of the examined Toninia candida extracts

\begin{tabular}{cccccc}
\hline \multicolumn{3}{c}{ Total phenolic content $(\mathrm{mg} \mathrm{GA} / \mathrm{g})$} & \multicolumn{3}{c}{ Total antioxidant capacity $(\mu \mathrm{g} \mathrm{AA} / \mathrm{g})$} \\
\hline methanol extract & chloroform extract & petrol ether extract & methanol extract & chloroform extract & petrol ether extract \\
$76.26 \pm 0.32$ & $45.25 \pm 0.72$ & $42.98 \pm 0.15$ & $78.45 \pm 0.58$ & $56.67 \pm 0.30$ & $51.45 \pm 0.31$ \\
\hline
\end{tabular}<smiles>COc1cc(C)c2c(c1C=O)Oc1c(c(C)c(O)c3c1C(O)OC3=O)OC2=O</smiles>

1<smiles>Cc1cc(O)c(C)c2c1Oc1c(C)c(C(=O)O)c(O)c(CO)c1OC2=O</smiles>

3<smiles>Cc1cc(O)c(C)c2c1C(=O)Oc1c(C)c(O)c3c(c1O2)C(O)OC3=O</smiles><smiles>CCOc1c(C)cc(OC(=O)c2c(C)cc(O)c(C=O)c2O)c(C)c1O</smiles> 
Table 4. The antioxidant activity of the examined extracts.

\begin{tabular}{|c|c|c|c|c|}
\hline \multirow[b]{2}{*}{ Lichen extracts/ standards } & \multicolumn{4}{|c|}{${ }^{\mathrm{a}} \mathrm{IC} 50(\mu \mathrm{g} / \mathrm{mL})$} \\
\hline & DPPH scavenging activity & $\begin{array}{l}\text { Inhibitory activity toward } \\
\text { lipid peroxidation }\end{array}$ & Metal chelating activity & $\begin{array}{l}\text { Hydroxyl radical } \\
\text { scavenging activity }\end{array}$ \\
\hline $\begin{array}{l}\text { Toninia candida } \\
\text { methanol extract }\end{array}$ & $51.45 \pm 1.78$ & $46.46 \pm 1.68$ & $41.91 \pm 0.88$ & $67,11 \pm 0.23$ \\
\hline $\begin{array}{l}\text { Toninia candida } \\
\text { chloroform extract }\end{array}$ & $48.98 \pm 1.45$ & $41.68 \pm 1.09$ & $40.45 \pm 0.45$ & $53.23 \pm 0.51$ \\
\hline $\begin{array}{l}\text { Toninia candida } \\
\text { petrol ether extract }\end{array}$ & $50.10 \pm 0.95$ & $21.45 \pm 1.55$ & $39.50 \pm 0,53$ & $50.57 \pm 0.75$ \\
\hline Gallic acid & $3.79 \pm 0.69$ & $255.43 \pm 11.68$ & - & $59.14 \pm 1.10$ \\
\hline Ascorbic acid & $6.05 \pm 0.34$ & $>1000$ & - & $160.55 \pm 2.31$ \\
\hline BHT & $15.61 \pm 1.26$ & $1.00 \pm 0.23$ & - & $33.92 \pm 0.79$ \\
\hline$\alpha$-Tocopherol & - & $0.48 \pm 0.05$ & - & - \\
\hline
\end{tabular}

\section{Acknowledgements}

This work was supported by the Ministry of Science and Environment of Serbia, projects No 172015 .

\section{References}

Carter P 1971. Spectrophotometric determination of serum iron at the submicrogram level with a new reagent-ferrozine. Anal Biochem 40: 450-458.

Correché E, Carrasco M, Giannini F, Piovano M, Garbarino J, Daniel E 2002. Cytotoxic screening activity of secondary lichen metabolites. Acta Farm Bonaer 21: 273-278.

Gulluce M, Aslan A, Sokmen M, Sahin F, Adiguzel A, Agar G, Sokmen A 2006. Screening the antioxidant and antimicrobial properties of the lichens Parmelia saxatilis, Platismatia glauca, Ramalina pollinaria, Ramalina polymorpha and Umbilicaria nylanderiana. Phytomedicine 13: 515-521.

Hidalgo ME, Fernández E, Quilhot W, Lissi E 1994. Antioxidant activity of depsides and depsidones. Phytochemistry 37: 1585-1587.

Hinneburg I, Dorman HJD, Hiltunen R 2006. Antioxidant activities of extracts from selected culinary herbs and spices. Food Chem 97: 122-129.

Hsu CK, Chiang BH, Chen YS, Yang JH, Liu CL 2008. Improving the antioxidant activity of buckwheat (Fagopyrum tataricm Gaertn) sprout with trace element water. Food Chem 108: 633-641.

Huneck S 1999. The significance of lichens and their metabolites. Naturwissenschaften 86: 559-570.

Huneck S, Yoshimura I 1996. Identification of lichen substances. Berlin: Springer, p. 168-183.

Katalinic V, Milos M, Kulisic T, Jukic M 2006. Screening of 70 medicinal plant extracts for antioxidant capacity and total phenols. Food Chem 94: 550-557.

Kumarasamy Y, Byres M, Cox PJ, Jaspars M, Nahar L, Sarker SD 2007. Screening seeds of some Scottish plants for free-radical scavenging activity. Phytother Res 21: 615621.

Manojlovic NT, Solujic S, Sukdolak S 2002. Antimicrobial activity of extract and anthraquinones from Caloplaca schaereri. Lichenologist 34: 83-85.

Manojlović NT, Vasiljević P, Jusković M, Najman S, Janković S, Milenković-Andjelković A 2010a. HPLC analysis and cytotoxic potential of extracts from the lichen, Thamnolia vermicularis var. subuliformis. J Med Plants Res 4: 817-823.

Manojlovic NT, Vasiljevic PJ, Gritsanapan W, Supabphol R, Manojlovic I 2010b. Phytochemical and antioxidant studies of Laurera benguelensis growing in Thailand. Biol Res 43:169-176.

Manojlovic NT, Vasiljevic PJ, Markovic ZS 2010c. Antimicrobial activity of extracts and various fractions of chloroform extract from the lichen Laurera benguelensis. J Biol Res-Thessalon 13: 27-34.

Markovic ZS, Manojlovic NT 2010. Analytical characterization of lichexanthone in lichen: HPLC, UV spectroscopic, and DFT analysis of lichexanthone extracted from Laurera benguelensis (Mull. Arg.) Zahlbr. Monatsh Chem 141: 945-952.

Narui T, Culberson CF, Culberson WL, Johnson A, Shibata S 1996. A contribution to the chemistry of the lichen family Umbilicariaceae (Ascomycotina). The Bryologist 99: 199-211.

Prieto P, Pineda M, Aguilar M 1999. Spectrophotometric quantitation of antioxidant capacity through the formation of a phosphomolybdenum complex: specific application to the determination of vitamin E. Anal Biochem 269: 337-341.

Saha M R, Hasan SMR, Akter R, Hossain MM, Alam MS, Alam MA, Mazumder MEH 2008. In vitro free radical 
scavenging activity of methanol extract of the leaves of Mimusops elengi Linn. Bangl J Vet Med 6: 197-202.

Shukla V, Joshi GP, Rawat MSM 2010. Lichens as a potential natural source of bioactive compounds. Phytochem Rev 9: 303-314.

Singleton V, Orthofer R, Lamuela-Raventos RM 1999. Analysis of total phenols and other oxidation substrates and antioxidants by means of Folin-Ciocalteu reagent. Method Enzymol 299: 152-175.

Takao T, Watanabe N, Yagi I, Sakata K 1994. A simple screening method for antioxidants and isolation of several antioxidants produced by marine bacteria from fish and shellfish. Biosci Biotechnol Biochem 58: 1780-1783.

Tay T, Özdemir Türk A, Y1lmaz M, Türk H, Kıvanc M 2004. Evaluation of the antimicrobial activity of the acetone extract of the lichen Ramalina farinacea and its (+)-usnic acid, norstictic acid, and protocetraric acid constituents. Z Naturforsch 59: 384-388.

Timdal E 1991. A monograph of the genus Toninia (Lecideaceae, Ascomycetes). Opera Bot 110: 1-137.

Yan LY, Teng LT, Jhi TJ 2006. Antioxidant properties of Guava fruits: comparison with some local fruits. Sunway Academic Journal 3: 9-20.

Yoshimura I, Kurokawa T, Kinoshita Y, Yamamoto Y, Miyawaki H 1994. Lichen substances in cultured lichens. J Hatt Bot Lab 76: 249-261.

\section{*Correspondence}

Nedeljko T. Manojlovic

Department of Pharmacy, Medical Faculty, University of Kragujevac

34000 Kragujevac, Serbia

ntm@kg.ac.rs 